\title{
The potential prognostic and predictive roles of programmed cell death protein 1 expressed by tumor-infiltrating lymphocytes in solid tumors: a meta-analysis
}

\author{
Dong-Yun Zhang ${ }^{1}$, Rong-Zhi Liư ${ }^{1}$, Jian-Wei Ku², Yu-Hong Ma', Ying-Jie Yi ${ }^{3}$ \\ 'Department of Basic Medicine, Nanyang Medical College, Nanyang 473061, Henan, China. \\ ${ }^{2}$ Department of Medical Oncology, The Second Affiliated Hospital of Nanyang Medical College, Nanyang 473061, Henan, China. \\ ${ }^{3}$ Department of Book Cataloguing, Nanyang Medical College, Nanyang 473061, Henan, China.
}

Correspondence to: Dr. Dong-Yun Zhang, Department of Basic medicine, Nanyang Medical College, Nanyang 473061, Henan, China. E-mail: zhangdy79@126.com

How to cite this article: Zhang DY, Liu RZ, Ku JW, Ma YH, Yi YJ. The potential prognostic and predictive roles of programmed cell death protein 1 expressed by tumor-infiltrating lymphocytes in solid tumors: a meta-analysis. $J$ Cancer Metastasis Treat 2018;4:16. http://dx.doi.org/10.20517/2394-4722.2018.01

Received: 2 Jan 2018 First Decision: 7 Feb 2018 Revised: 14 Feb 2018 Accepted: 28 Mar 2018 Published: 12 Apr 2018

Science Editors: Pravin D. Potdar, Shuen-Kuei Liao Copy Editor: Jun-Yao Li Production Editor: Cai-Hong Wang

\begin{abstract}
Aim: Several previous studies have evaluated the potential role of programmed cell death protein 1 (PD-1) expressed by tumor-infiltrating lymphocytes (TILs) in various solid tumors and performed its prognosis role in patients' survival with inconsistent results. This study aims to further systematically evaluate the association of PD-1 by TILs with clinicopathological parameters and clinical outcomes in solid tumor patients.
\end{abstract}

Methods: A comprehensive search was conducted in PubMed, Embase, Web of Science, CNKI and Wanfang databases for relevant studies. The potential prognostic and predictive roles of PD-1 were assessed by pooled hazard ratio (HR), odds ratio (OR) and 95\% confidence intervals $(\mathrm{Cl})$. A total of 1863 patients were selected for in-depth analysis.

Results: The results demonstrated that PD-1 by TILs was correlated to overall survival for ovarian cancer $(H R=0.40$, 95\% Cl: 0.26-0.61, $P<0.00001)$. Higher PD-1 expression was associated with lymph node metastasis $(\mathrm{OR}=2.55$, $95 \% \mathrm{Cl}: 1.22-5.29, P=0.01)$ and tumor grade (OR $=3.08,95 \% \mathrm{Cl}: 2.07-4.57, P<0.00001)$.

Conclusion: The prognostic role of PD-1 by TILs is variant in different tumor types, which highlights the role of PD-1 by TILs as a potential predictive and prognostic biomarker and the development of strategies against the PD-L1/PD-1 axis would be a promising therapeutic target for some solid tumors.

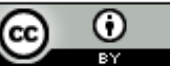

(C) The Author(s) 2018. Open Access This article is licensed under a Creative Commons Attribution 4.0 International License (https://creativecommons.org/licenses/by/4.0/), which permits unrestricted use, sharing, adaptation, distribution and reproduction in any medium or format, for any purpose, even commercially, as long as you give appropriate credit to the original author(s) and the source, provide a link to the Creative Commons license, and indicate if changes were made.

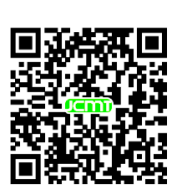


Keywords: Programmed cell death protein 1, meta-analysis, solid tumors, prognosis

\section{INTRODUCTION}

Programmed cell death protein 1 (PD-1), a member of the CD28 receptor family, is expressed by activated lymphocytes and inhibits their proliferation functions after binding to PD-1 ligands such as PD-L $1^{[1]}$. The interactions with PD-1/PD-L1 signaling has been shown to improve clinical outcome and restore functional T-cell responses in several cancers ${ }^{[2]}$.

Although PD-1 has generated increasing interest as a target for immune modulation in cancers, the prognostic values of PD-1 expressed by tumor-infiltrating lymphocytes (TILs) in solid tumors were still unclear $^{[3]}$. Several previous studies have reported the PD-1 by TILs is more than a predictive biomarker but as a worse prognosis marker in multiple solid tumors such as gastric cancer ${ }^{[4]}$, non-small cell lung cancer $(\mathrm{NSCLC})^{[5]}$, renal cell cancer ${ }^{[6]}$ and nasopharyngeal cancer ${ }^{[7]}$. Another studies showed that PD-1 expression is associated with favorable survival in breast cancer $^{[8]}$, glioblastoma ${ }^{[9]}$, metastatic melanoma ${ }^{[10]}$, ovarian cancer $^{[11]}$ and primary human papillomavirus-positive head and neck cancers ${ }^{[12]}$. Furthermore, one study displayed that the positive expression of PD-1 expression is not correlated with overall survival (OS) for esophageal squamous cell carcinoma (ESCC) ${ }^{[13]}$. The different of tissue samples, detection methods and evaluation criterions might be partly responsible for the inconsistent results.

And with the development of PD-L1/PD-1 targeted therapy, some predictive and prognostic biomarkers are crucial to be identified for the option of individualized anti-PD-1 targeted treatment ${ }^{[14]}$. Therefore, we conducted this meta-analysis to comprehensively evaluate the prognostic value of PD-1 by TILs in solid tumors, which will further facilitate the development of PD-L1/PD-1 immune check-point targeted therapy and identify novel strategies targeting PD-1.

\section{METHODS}

\section{Publication searching}

The eligible studies published in PubMed, Embase, Web of Science, CNKI and Wanfang databases were searched using the following keywords: "programmed cell death 1 receptor" or "PD-1" or "programmed death 1" or "CD279 antigen" and "cancer" or "tumor" or "neoplasm" or "carcinoma" and "prognosis" or "outcome" or "survival". In addition, we also manually screened the reference lists derived from randomized controlled trials and systematic review to avoid omitting related publications. The search language was limited to English and Chinese.

\section{Inclusion and exclusion criteria}

Inclusion criteria for this meta-analysis are: (1) full text available; (2) study focus on the association of PD-1 with clinicopathological parameters and OS; (3) cohort study, cross-sectional study or case-control study; (4) sufficient data or higher dots per inch of K-M survival curves. In addition, the exclusion criteria are as follows: (1) cell or animal studies; (2) case reports or review; (3) conference abstracts or comments; (4) repeated articles.

\section{Data extraction and quality assessment}

Two investigators (Liu RZ and Ku JW) independently extracted the data from the relevant studies. The disagreements were resolved by consensus. The extracted data are as follows: first author name, publication year, patient source, cancer type, number of patients, detection method, clinicopathological parameters, effect size, hazard ratio (HR) and 95\% confidence intervals (CI). The quality of eligible studies were assessed through the Newcastle-Ottawa scale (NOS) method ${ }^{[15]}$. Study with NOS scores above to 6 point were usually considered to be higher quality. 
Table 1. Features of included studies

\begin{tabular}{|c|c|c|c|c|c|c|c|c|c|}
\hline Authors & Year & Country & Cancer type & $\begin{array}{c}\text { No. of } \\
\text { patients }\end{array}$ & $\begin{array}{l}\text { PD-1(+) } \\
\text { patients }\end{array}$ & $\begin{array}{c}\text { Clinicopathological } \\
\text { parameters }\end{array}$ & $\begin{array}{l}\text { Effect } \\
\text { size }\end{array}$ & $\begin{array}{c}\text { HR, } \\
95 \% \mathrm{Cl}\end{array}$ & $\begin{array}{l}\text { NOS } \\
\text { score }\end{array}$ \\
\hline Badoual et al. ${ }^{[12]}$ & 2013 & France & HNSCC & 64 & $31 / 33(++/+)$ & NR & OS & Yes & 7 \\
\hline Feng et al. ${ }^{[13]}$ & 2016 & China & ESCC & 88 & 45 & $B, C, D, E, G$ & OS & Yes & 6 \\
\hline Zheng et al. ${ }^{[22]}$ & 2016 & China & NSCLC & 42 & $15 / 27(++/+)$ & $\mathrm{B}, \mathrm{H}, \mathrm{I}$ & OS & NR & 7 \\
\hline Shen et al. ${ }^{[23]}$ & 2017 & China & Pancreatic cancer & 94 & $47 / 47(++/+)$ & $A, B, C, D, E, G$ & OS & Yes & 7 \\
\hline Harter et al. ${ }^{[24]}$ & 2015 & Germany & NSCLC & 62 & $18 / 44(++/+)$ & NR & OS & NR & 6 \\
\hline Webb et $a l^{[25]}$ & 2015 & Canada & Ovarian cancer & 195 & 75 & NR & OS & Yes & 6 \\
\hline Duchnowska et al. ${ }^{[27]}$ & 2016 & Poland & Breast cancer & 84 & 17 & NR & OS & Yes & 6 \\
\hline Chen et $a l^{[28]}$ & 2016 & China & ESCC & 349 & 117 & $A, B, C, D, E, F$ & OS & Yes & 7 \\
\hline Muenst et al. ${ }^{[29]}$ & 2013 & USA & Breast cancer & 660 & 104 & $C, D, E, G$ & OS & Yes & 6 \\
\hline Sun et $a{ }^{[30]}$ & 2015 & China & ESCC & 225 & 69 & $A, B, C, D$ & OS & Yes & 6 \\
\hline
\end{tabular}

HNSCC: head and neck squamous cell carcinoma; NSCLC: non-small cell lung cancer; ESCC: esophageal squamous cell carcinoma; NR: not reported; A: age; B: gender; C: tumor invasion depth; D: lymph node metastasis; E: tumor stage; F: tumor location; G: tumor grade; $H$ : histology type; I: treatment method; OS: overall survival; HR: hazard ratios; Cl: confidence interval; NOS: Newcastle-Ottawa scale

\section{Statistical analysis}

All statistical analysis were conducted using the RevMan5.2 and STATA version 12.0 (STATA Corporation, College Station, TX, USA). HR and 95\% CI were combined to assess the survival impact of PD-1 in solid tumors. For studies that offered only Kaplan-Meier curves, Engauge Digitizer (version 4.1) was performed to extract the survival data and calculate the estimated HRs and $95 \%$ CIs according to Tierney's method ${ }^{[16]}$. Additionally, pooled odds ratio (OR) and $95 \%$ CI were used to determine the association of PD-1 and clinicopathological features.

Heterogeneity is assessed using Cochrane's $Q$ test and $I^{2}$ measurement (no heterogeneity, $I^{2}=0 \%-25 \%$; low heterogeneity, 25\%-50\%; moderate heterogeneity, 50\%-75\%; high heterogeneity, $75 \%-100 \%)^{[17]}$. $P<0.1$ or $I^{2}>50 \%$ indicate a significant heterogeneity. Random effects model was initially applied to combine the estimates of effect ${ }^{[18]}$. Otherwise, a fixed effects model was utilized ${ }^{[19]}$. Sensitivity analysis was used to illustrate any significant heterogeneity among studies. Begg ${ }^{2}{ }^{[20]}$ and Egger's test ${ }^{[21]}$ were deemed to explain publication bias with $P$ value of less than 0.05 .

\section{RESULTS}

\section{Characteristics of included studies}

A total of 701 studies were identified by electronic search and 388 studies were excluded because of duplication. After reading the titles and abstracts, 221 studies were excluded and 92 possible full text studies were carefully reviewed. Finally, 10 manuscripts containing 12 retrospective cohort studies were included for quantitative analysis in the meta-analysis [Figure 1]. The patients were diagnosed with various solid cancers including: ESCC, NSCLC, hepatocellular carcinoma, pancreatic cancer, breast cancer and ovarian cancer. The features of included studies were presented in Table 1.

To detect the expression of PD-1 by TILs, all studies used immunohistochemistry, except for 2 studies ${ }^{[22,23]}$, which used quantitative immunofluorescence, but the proportion of PD-1 expression was consistent with the others in that study. The detailed methodologies used to detect PD-1 are summarized in Table 2. Furthermore, 2 cohorts of patients were reported by Harter et al. ${ }^{[24]}$ and Webb et al. ${ }^{[25]}$, respectively. PD-1 by TILs was assessed and the survival curves were reported independently, so they have been statistically analyzed as 4 individual studies.

\section{PD-1 by TILs and overall analysis}

A total of 12 studies with 1863 patients were enrolled in survival analysis. Seven studies with data on PD-1 positive expression and OS in solid tumors. There are 2 studies provided OS for breast cancer $(2$ cohort 


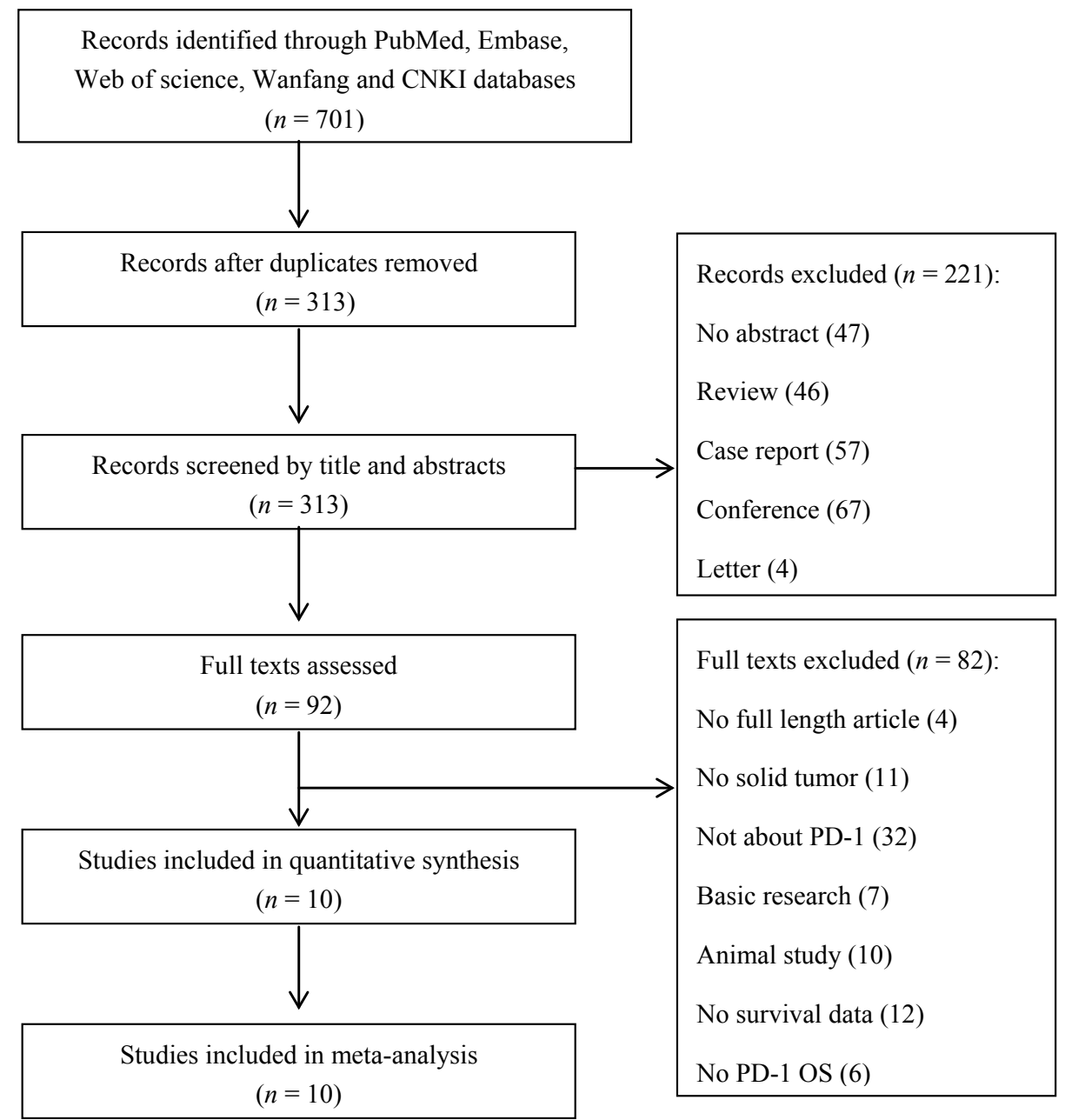

Figure 1. Flow diagram for selection of studies. PD-1: programmed cell death protein 1; OS: overall survival

Table 2. Evaluation of human PD-1 by immunohistochemistry

\begin{tabular}{|c|c|c|c|c|c|}
\hline Authors & Detection method & Antibody clone & Antibody dilution & Antibody source & Cutoff value \\
\hline Badoual et al..$^{[12]}$ & $\mathrm{IHC}$ & CT-011 & $1: 100$ & CureTech LTD & NR \\
\hline Feng et al. ${ }^{[13]}$ & $\mathrm{IHC}$ & NR & NR & NR & NR \\
\hline Zheng et al. ${ }^{[22]}$ & IFC & NR & NR & BioLegend & $>12.27 \%$ of cells \\
\hline Shen et $a{ }^{[23]}$ & IFC & AB52587 & $1: 200$ & Abcam & NR \\
\hline Harter et al. ${ }^{[24]}$ & $\mathrm{IHC}$ & NAT-105 & $1: 50$ & Abcam & Total score $>1^{\mathrm{a}}$ \\
\hline Webb et al. ${ }^{[25]}$ & $\mathrm{IHC}$ & NAT-105 & $1: 200$ & Biocare Medical & NR \\
\hline Duchnowska et al. ${ }^{[27]}$ & $\mathrm{IHC}$ & NBP1-88104 & $1: 100$ & Novus & Total score $>1^{b}$ \\
\hline Chen et al. ${ }^{[28]}$ & $\mathrm{IHC}$ & NAT105 & $1: 100$ & Abcam & Total score $>1^{b}$ \\
\hline Muenst et al. ${ }^{[29]}$ & $\mathrm{IHC}$ & MRQ-22 & $1: 50$ & Rocklin & NR \\
\hline Sun et al. ${ }^{[30]}$ & $\mathrm{IHC}$ & MRQ-22 & $1: 100$ & Abcam & Total score $>1^{b}$ \\
\hline
\end{tabular}

${ }^{a}$ All samples were scored according to the frequency of positive cells related to all cells (as percentage) on the stained TMA core: frequency $0-1 \%$ score $0 ; 1 \%-10 \%$ score $1 ; 10 \%-25 \%$ score $2 ; 25 \%-50 \%$ score $3 ;>50 \%$ score 4 ; additionally we multiplied the frequency score with the intensity of staining ( 1 weak staining, 2 moderate staining, 3 strong staining). ${ }^{b}$ Total score was calculated by adding a score of staining percentage to another score of staining intensity. The area of staining was scored as 0 (no tumor cells stained), $1(<25 \%$ of cells stained), 2 ( $\geq 25 \%$ of cells stained). Staining intensity was graded as 0 (no staining), 1 (weak staining), 2 (moderate staining), 3 (strong staining). PD-1: programmed cell death protein 1; IHC: immunohistochemistry; IFC: immunofluorescence; NR: not reported

studies in the same one paper), 3 studies for ESCC and 2 studies for ovarian cancer. A random effect model was used to calculate the pooled HR and 95\% CI due to the high heterogeneity $\left(P<0.0001, I^{2}=83 \%\right)$. The results showed that PD-1 expression was not associated with patients OS (HR $=0.86,95 \%$ CI: $0.56-1.31, P=0.47)$ 


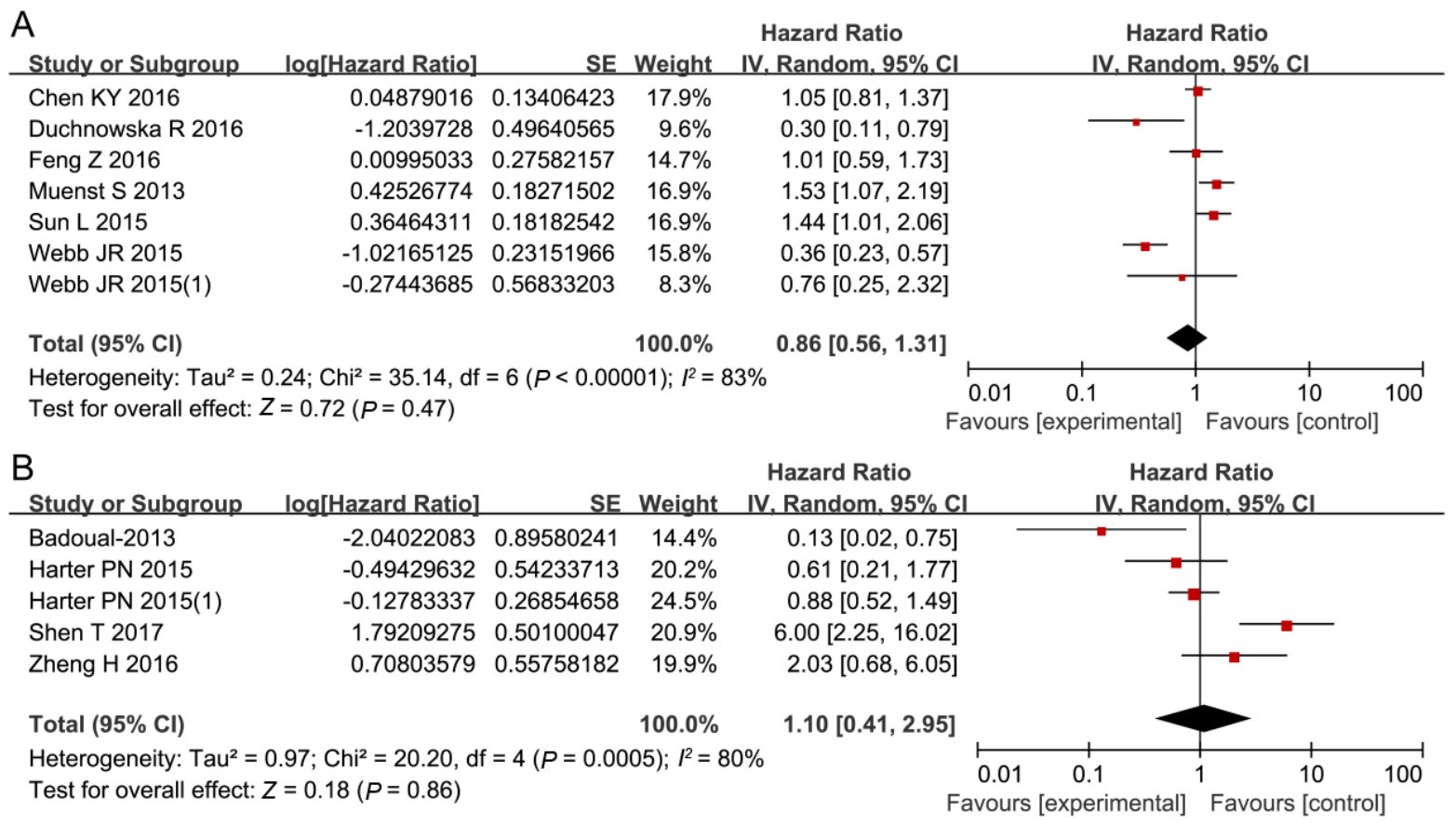

Figure 2. Forest plots of PD-1 expression and OS in solid tumor patients. The squares and horizontal lines correspond to the study-specific $\mathrm{HR}$ and $95 \% \mathrm{Cl}$. The area of the square reflects the study-specific weight. The diamonds represents the pooled OR and $95 \% \mathrm{Cl}$. The solid vertical line is at the null value $(H R=1)$. The associations between positive or negative expression of PD-1 $(A)$ and strong or moderate positive expression of PD-1 (B) with OS are shown. PD-1: programmed cell death protein 1; OS: overall survival; HR: hazard ratio; OR: odds ratio; $\mathrm{Cl}$ : confidence interval

[Figure 2A]. Another 5 studies provided data on PD-1 high or low expression and OS. There are 2 studies provided OS for NSCLC, 1 study for head and neck squamous cell carcinoma, 1 study for pancreatic cancer and 1 study for melanoma. The pooled HR was $1.10(95 \% \mathrm{CI}$ : 0.41-2.95, $P=0.65)$ in solid tumor patients with high heterogeneity $\left(I^{2}=80 \%, P=0.0005\right)$ [Figure $2 \mathrm{~B}$ ].

\section{PD-1 by TILs and subgroup analysis}

We also conducted subgroup meta-analysis to explore the possible source of heterogeneity. In the subgroup analysis stratified by patients source, pooled HR estimate for OS was 1.15 (95\% CI: 0.94-1.40, $P=0.16$ ) for Asian patients with low heterogeneity $\left(I^{2}=10 \%, P=0.33\right.$ ) [Figure 3A], and 0.61 (95\% CI: 0.24-1.56, $\left.P=0.30\right)$ for non-Asian patients with high heterogeneity $\left(I^{2}=89 \%, P<0.0001\right)$ [Figure $3 \mathrm{~B}$ ]. In the stratified analysis by cancer type, there are 2 studies provided OS for breast cancer, 3 studies for ESCC and 2 studies for ovarian cancer. There was no significant association between PD-1 expression and patients OS of breast cancer ( $\mathrm{HR}=0.72,95 \% \mathrm{CI}$ : 0.15-3.55, $P=0.69$ ) [Figure 4A] and ESCC ( $\mathrm{HR}=1.15,95 \% \mathrm{CI}$ : 0.94-1.40, $P=0.16)$ [Figure 4B]. With no significant heterogeneity $\left(P=0.22, I^{2}=33 \%\right)$, a fixed-effects model was conducted to evaluate their relationship for ovarian cancer. The results found that PD-1 expression was statistically significantly associated with patients OS (HR $=0.40,95 \%$ CI: 0.26-0.61, $P<0.00001$ ) [Figure 4 C].

\section{PD-1 by TILs and clinicopathological parameters}

The average positive expression rates of PD-1 by TILs were $31.35 \%$ in all of the studies. There were the higher PD-1 overexpression in NSCLC, ESCC and pancreatic cancer, with accounting for $35.71 \%, 61.23 \%$ and 50.01\%, respectively. And PD-1 expression levels in melanoma, breast cancer and ovarian cancer ranged from $8.59 \%$ to $22.97 \%$.

Four studies including 1209 tissue samples investigated the association of PD-1 overexpression with status of lymph node. With significant heterogeneity $\left(P=0.0008, I^{2}=82 \%\right)$, a random-effects model showed a 


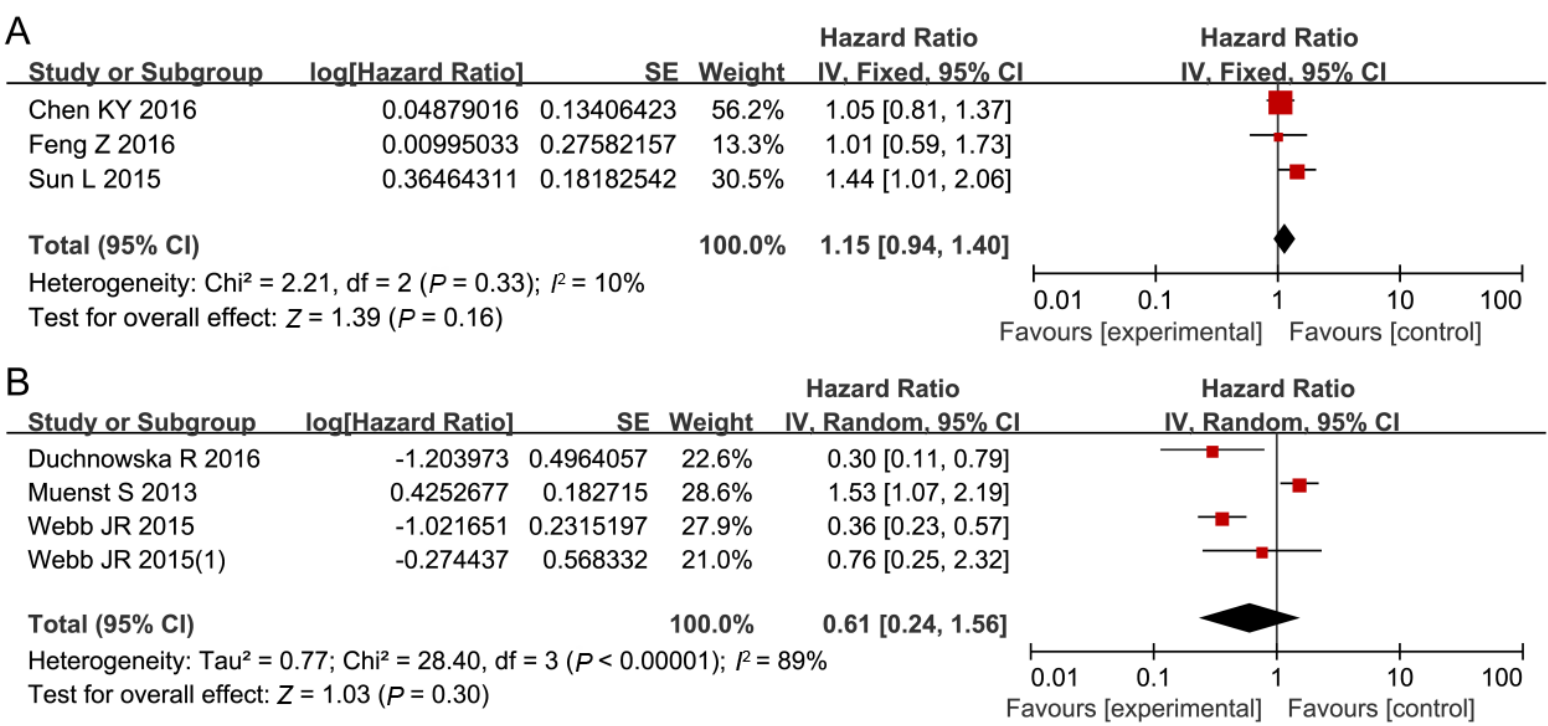

Figure 3. Forest plots for subgroup meta-analysis by patient source. The relationships between PD-1 overexpression and OS in Asia patients (A) and in non-Asia patients (B) are shown. PD-1: programmed cell death protein 1; OS: overall survival; Cl: confidence interval

A

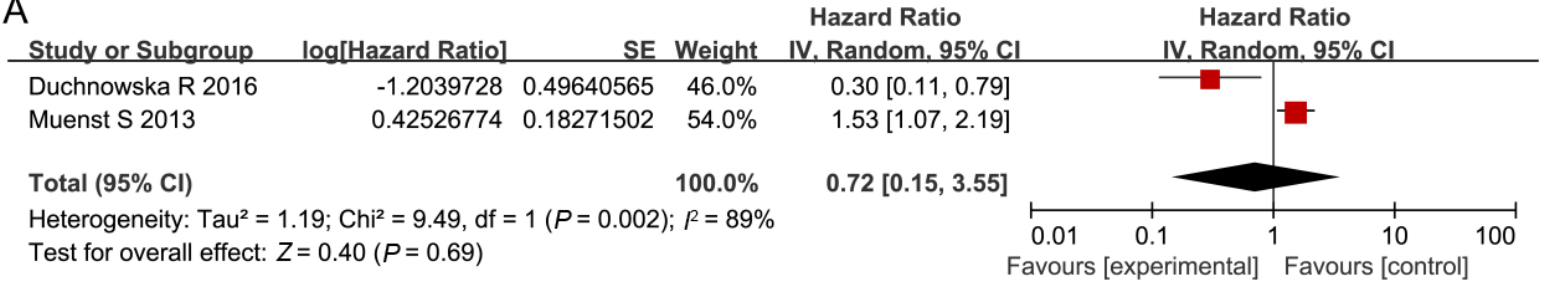

B

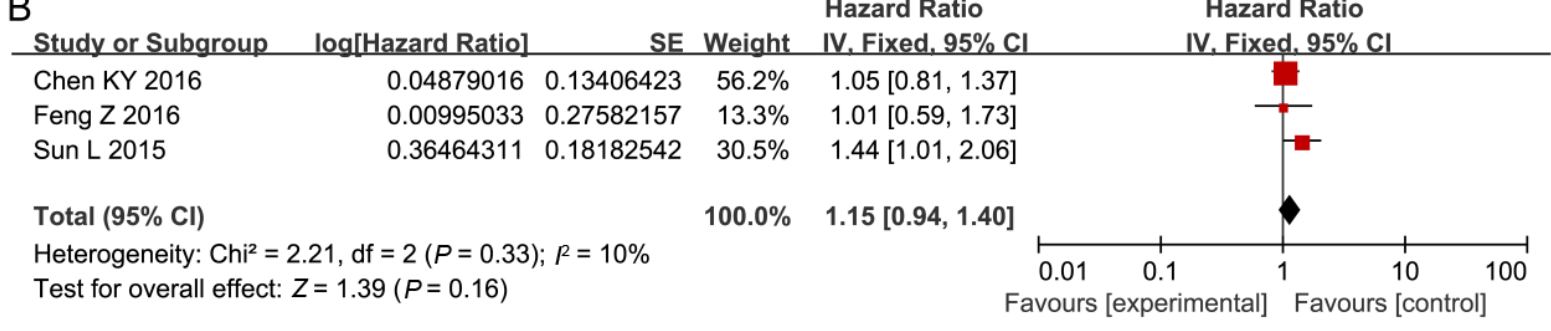

C

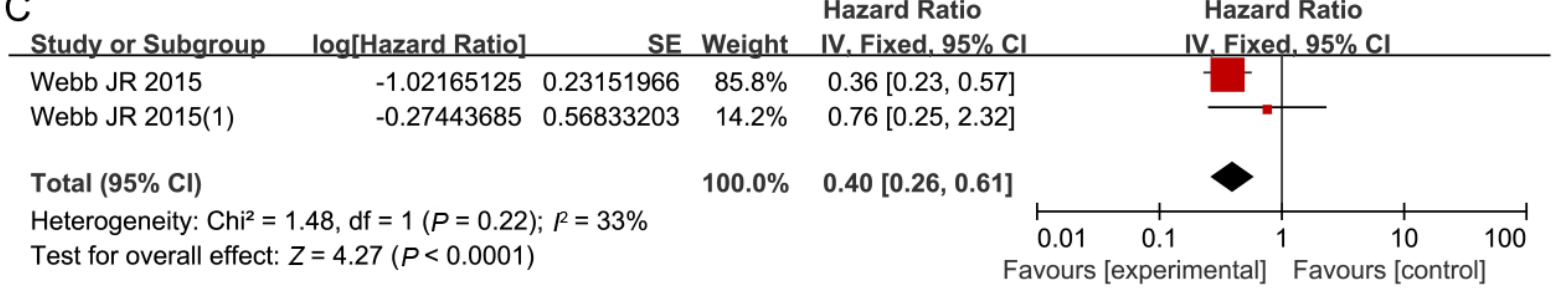

Figure 4. Forest plots for subgroup meta-analysis stratified by cancer type. The relationships between PD-1 expression and OS in breast cancer (A), ESCC (B) and ovarian cancer (C) are shown. PD-1: programmed cell death protein 1; OS: overall survival; ESCC: esophageal squamous cell carcinoma; $\mathrm{Cl}$ : confidence interval

significant difference between lymph node metastasis group (35.0\%) and lymph node non-metastasis group (21.4\%) $(\mathrm{OR}=2.55,95 \% \mathrm{CI}: 1.22-2.59, P=0.01)$ [Figure 5A]; 3 studies reported the relationship of PD-1 overexpression with tumor grade. With no significant heterogeneity $\left(P=0.92, I^{2}=0 \%\right)$, a fixed-effects model was used in the study. The results revealed a significant difference between 274 grade $3 / 4$ tissues $(28.1 \%)$ and 


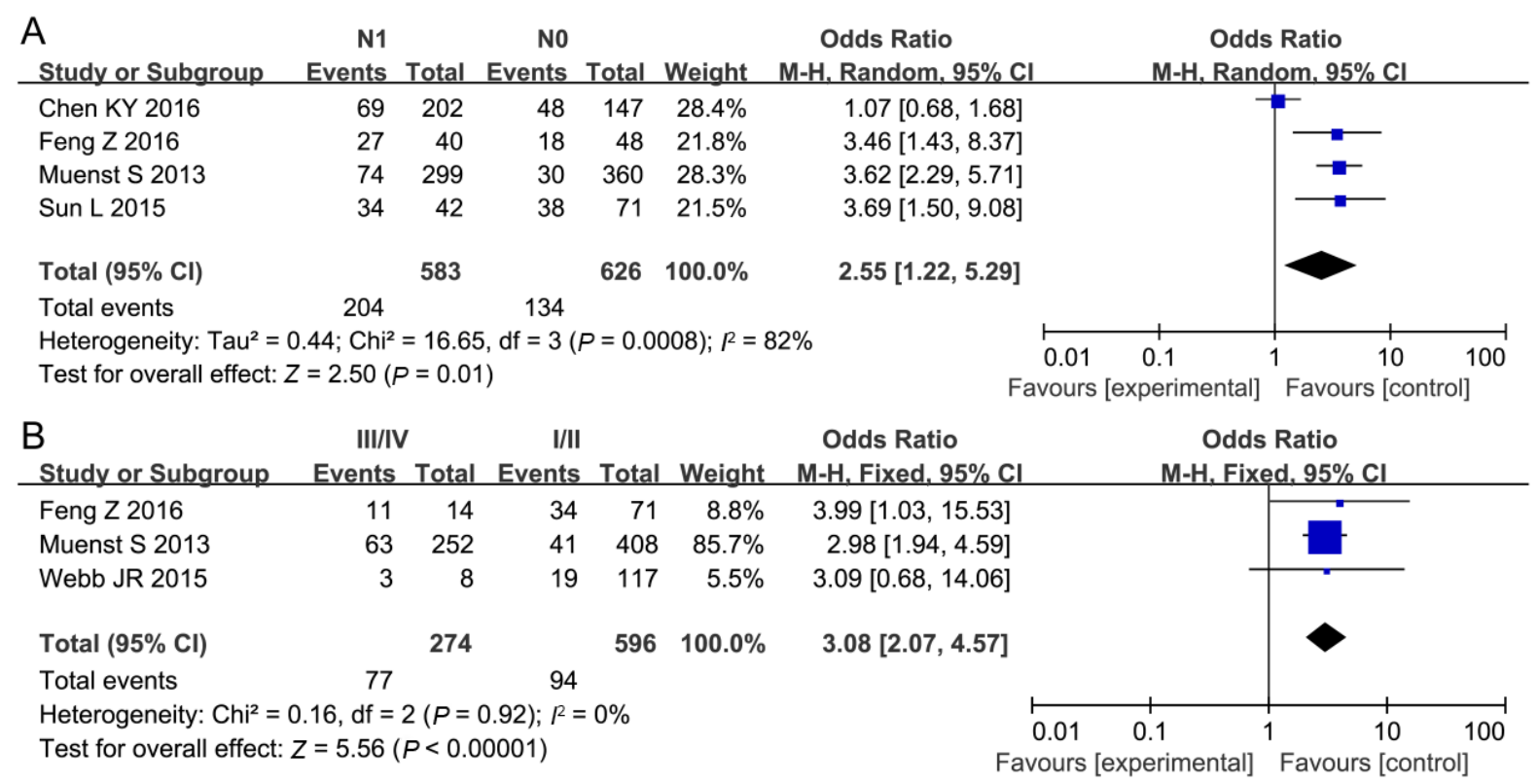

Figure 5. Forest plots of PD-1 expression and the clinical pathological parameters of patients with solid tumors. The squares and horizontal lines correspond to the study-specific OR and $95 \% \mathrm{Cl}$. The area of the square reflects the study-specific weight. The diamonds represents the pooled $\mathrm{OR}$ and $95 \% \mathrm{Cl}$. The solid vertical line is at the null value $(\mathrm{OR}=1)$. The associations of PD-1 expression with lymph node status (A) and tumor grade (B) are shown. PD-1: programmed cell death protein 1; OR: odds ratio; $\mathrm{Cl}$ : confidence interval

Table 3. Associations of PD-1 expression and clinical features

\begin{tabular}{|c|c|c|c|c|c|c|}
\hline Variables & No. of study & OR ( $95 \% \mathrm{Cl})$ & $Z, P(\mathrm{OR})$ & $\begin{array}{c}\text { Heterogeneity } \\
\left(I^{2}, \text { P bias }\right)\end{array}$ & $\begin{array}{c}\text { Publication bias } \\
\text { (Egger test) }(t, P)\end{array}$ & Pooling model \\
\hline Age (years): $\leq 65$ vs. $>65$ & 2 & $1.20(0.48-3.02)$ & $0.39,0.70$ & $73 \%, 0.06$ & - & Random \\
\hline Gender: male vs. female & 3 & $0.96(0.78-1.18)$ & $0.36,0.72$ & $0 \%, 0.81$ & $0.42,0.748$ & Fixed \\
\hline $\mathrm{T}: \mathrm{T} 3 / \mathrm{T} 4$ vs. T1/T2 & 4 & $1.17(0.61-2.24)$ & $0.48,0.64$ & $91 \%, 0.000$ & $0.57,0.627$ & Random \\
\hline $\begin{array}{l}\text { Lymph node metastasis: } \\
\text { yes vs. no }\end{array}$ & 4 & $2.55(1.22-2.59)$ & $2.05,0.01^{\star}$ & $82 \%, 0.0008$ & $1.09,0.389$ & Random \\
\hline Tumor grade: $3 / 4$ vs. $1 / 2$ & 3 & $3.08(2.07-4.57)$ & $5.56,<0.0001^{\star}$ & $0 \%, 0.92$ & $0.12,0.923$ & Fixed \\
\hline TNM stage: III/IV vs. I/II & 4 & $1.04(0.71-1.54)$ & $0.21,0.84$ & $0 \%, 0.93$ & $3.38,0.077$ & Fixed \\
\hline
\end{tabular}

*Statistical significance. PD-1: programmed cell death protein 1; OR: odds ratio; Cl: confidence interval

596 grade $1 / 2$ tissues $(15.8 \%)(\mathrm{OR}=3.08,95 \%$ CI: 2.07-4.57, $P<0.00001)$ [Figure $5 \mathrm{~B}$ ]. We did not find the significant association of PD-1 with age, TNM stage or tumor invasion depth in solid tumor [Table 3].

\section{Publication bias}

Begg's and Egger's test were applied to evaluate the publication bias of the included studies. No obvious asymmetry was presented through the visual assessment of the Begg's funnel plots [Figure 6]. Furthermore, the formal evaluation of Egger's test also failed to find the significant bias $(P=0.723)$.

\section{Sensitivity analysis}

Sensitivity analysis was conducted to justify the influence of individual study on the synthetic results of OS. The pooled HR was not significantly influenced after omitting any singly study for the effect of PD-1 expression on OS in our study [Figure 7].

\section{DISCUSSION}

PD-1, as one of the co-inhibitory receptors, plays an important role in cancer immunity equilibrium and immunity escape stages $^{[26]}$. In the present study, we comprehensively assessed the association of PD-1 


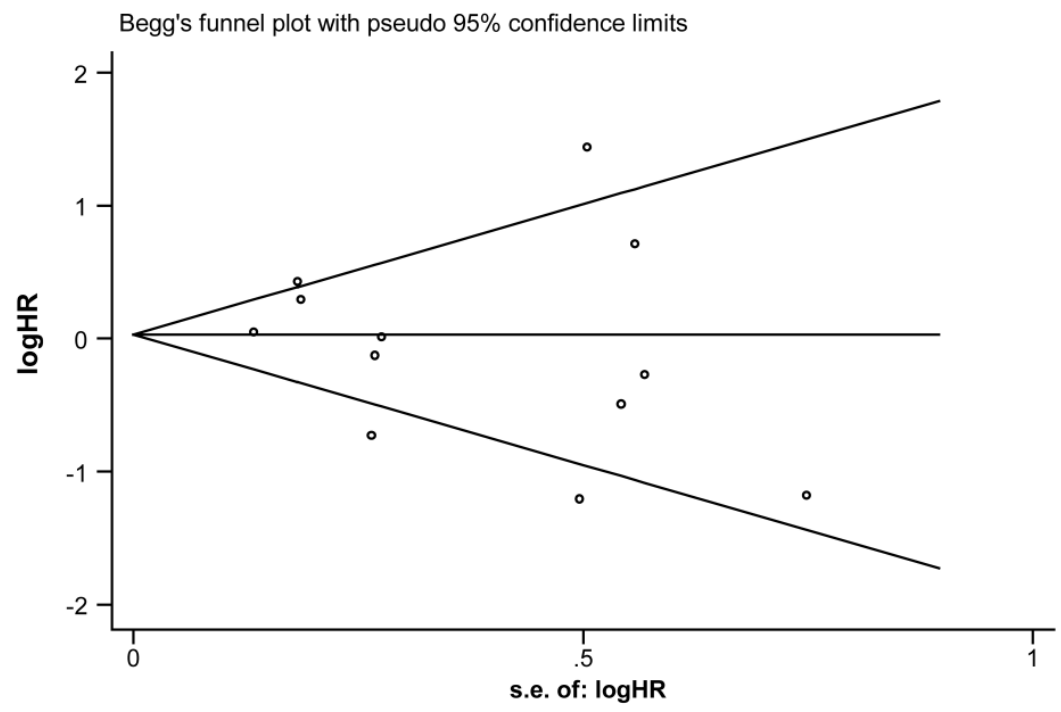

Figure 6. Begg's funnel plot for publication bias analysis. HR: hazard ratio

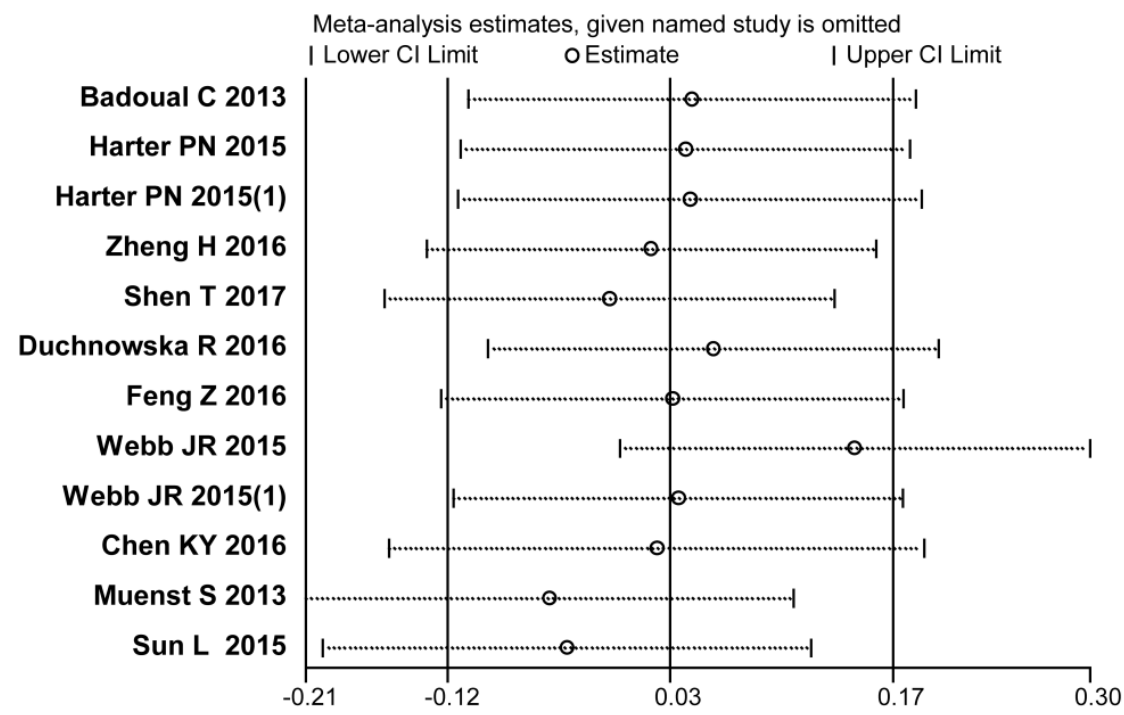

Figure 7. Sensitivity analysis of the meta-analysis. Cl: confidence interval

expressed by TILs with OS in solid tumor and revealed that the prognostic role of PD-1 by TILs is variant in different solid tumor types. This study included 10 eligible publications with 12 cohort studies and a total of 1863 patients. To the best of our knowledge, this is the first systematic assessment of the association of PD-1 by TILs with OS in solid tumor.

With respect to the tumor type, when we performed the subgroup meta-analysis stratified by tumor types, ovarian cancer was correlated with better survival for patients with high PD-1 levels rather than other solid tumor. Although PD-1 by TILs was not associated with OS for all of included studies in the metaanalysis $^{[12,13,22-30]}$. However, the results of studies using different clone to PD-1 antibodies were controversy in breast cancer ${ }^{[27,29]}$ [Supplementary Figure 1] in our meta-analysis. One recent study reported the opposite results using variant PD-L1 antibodies in melanoma and lung cancer ${ }^{[14]}$. The difference of antibody clones, limited specificity, or distinct IHC protocols used may be partly explain the contradictory results ${ }^{[31]}$. Further studies are urgent to clarify the impact of antibodies on the results of studies. 
Another important finding in the present study is that patients with lymph node metastasis and tumor grade $3 / 4$ have higher PD-1 by TILs than patients with non-lymph node metastasis and $1 / 2$ tumor grade. It is known that tumor grade and lymph node metastasis are usually major barriers to cancer treatment. And patients developed lymph node metastasis and tumor grade $3 / 4$ have lower survival rates. To a certain extent, PD-1 by TILs may be contributed to the immunosuppression to aggravate the tumor growth and carcinogenesis, and further negatively affecting patients' survival. One study in clinical trials showed that $\mathrm{PD}-1$-positive tumors tend to be more responsive to anti-PD-1 or anti-PD-L1 therapies ${ }^{[32]}$. It is reasonable to suggest that patients with lymph node metastasis and tumor grade $3 / 4$ seem to be more sensitive to anti-PD-1 or anti-PD-L1 antibodies-based therapies.

Besides, PD-L1 expression state is another key point of PD-1/PD-L1-mediated tumor immune escape. In tumor tissues, PD-1 was mainly expressed by TILs, and PD-L1 was detected by both tumor cells and TILs ${ }^{[33]}$. PD-1 by TILs was significantly correlated with PD-L1 expressed by tumor cells ${ }^{[34,35]}$. Furthermore, the findings that PD-L1-positive TILs in cancer provides a suitable microenvironment for the development of tumor growth and treatment resistance, which was known to be mediated by the induction of activated IL- 6 signaling ${ }^{[36,37]}$. Although immunotherapy using recombinant antibodies and vaccines, such as the therapies targeting PD-L1/PD-1, have been linked with prognosis and treatment response for a few solid tumors including a number of GI malignancies ${ }^{[38,39]}$, the expression of PD-L1 by CIK cells, TILs, and tumor cells within the tumor microenvironment remains to be elucidated.

Although the quality assessment of included studies is higher, there are still some limitations in the study. First of all, the quality of included studies is with selection bias due to the deletion of some unqualified literatures. Secondly, the screening of language is only English and Chinese and could not represent the whole population. Thirdly, the research objects are mainly cancerous tissues and the potential role of PD-1 in blood specimen remains unclear. Finally, the sample size in some of studies is small and further studies with larger sample size are still needed.

In conclusion, this meta-analysis demonstrates that PD-1 expressed by TILs is associated with lymph node metastasis and tumor grade in solid tumor. And more importantly, the prognostic role of PD-1 is variant in different solid tumors, which assumed that PD-1 by TILs seems to be a potential predictive biomarker and the development of strategies against the PD-L1/PD-1 axis would be a promising therapeutic target for some solid tumors.

\section{DECLARATIONS}

\section{Acknowledgments}

We thank Prof. Liang Wang at Medical College of Wisconsin (E-mail: liwang@mcw.edu) to help us polishing the whole manuscript in English.

\section{Authors' contributions}

Conception and design: Zhang DY, Liu RZ, Ku JW, Ma YH, Yi YJ

Manuscript writing: Zhang DY, Liu RZ, Ku JW, Ma YH

Manuscripts review and editing: Zhang DY

\section{Data source and availability}

Data are searched in PubMed, Embase, Web of Science, CNKI and Wanfang databases.

\section{Financial support and sponsorship}

This work was funded by the High-Tech Key Projects of Science and Technology of Henan Province Government (152102310230), the High-Tech Key Projects of High School of Henan Province (17B320012) and the Doctoral Scientific Fund Project of Nanyang Medical College (2015NYYZBSJJ01). 


\section{Conflicts of interest}

All authors declare no conflicts of interest.

\section{Patient consent}

Not applicable.

\section{Ethics approval}

Not applicable.

\section{Copyright}

(c) The Author(s) 2018.

\section{REFERENCES}

1. Dong H, Strome SE, Salomao DR, Tamura J, Hirano F, Flie DB, Roche PC, Lu J, Zhu G, Tamada K, Lennon VA, Celis E, Chen L. Tumor-associated B7-H1 promotes T-cell apoptosis: a potential mechanism of immune evasion. Nat Med 2002;8:793-800.

2. Pardoll DM. The blockade of immune checkpoints in cancer immunotherapy. Nat Rev Cancer 2012;12:252-64.

3. Lu P, Youngblood BA, Austin JW, Mohammed AU, Butler R, Ahmed R, Boss JM. Blimp-1 represses CD8 T cell expression of PD-1 using a feed-forward transcriptional circuit during acute viral infection. J Exp Med 2014;211:515-27.

4. Qing Y, Li Q, Ren T, Xia W, Peng Y, Liu GL, Luo H, Yang YX, Dai XY, Zhou SF, Wang D. Upregulation of PD-L1 and APE1 is associated with tumorigenesis and poor prognosis of gastric cancer. Drug Des Devel Ther 2015;9:901-9.

5. Anagnostou VK, Brahmer JR. Cancer immunotherapy: a future paradigm shift in the treatment of non-small cell lung cancer. Clin Cancer Res 2015;21:976-84.

6. Xu F, Xu L, Wang Q, An G, Feng G, Liu F. Clinicopathological and prognostic value of programmed death ligand-1 (PD-L1) in renal cell carcinoma: a meta-analysis. Int J Clin Exp Med 2015;8:14595-603.

7. Hsu MC, Hsiao JR, Chang KC, Wu YH, Su IJ, Jin YT. Increase of programmed death-1-expressing intratumoral CD8 T cells predicts a poor prognosis for nasopharyngeal carcinoma. Mod Pathol 2010;23:1393-403.

8. Baptista MZ, Sarian LO, Derchain SF, Pinto GA, Vassallo J. Prognostic significance of PD-L1 and PD-L2 in breast cancer. Hum Pathol 2016;47:78-84.

9. Liu Y, Carlsson R, Ambjorn M, Hasan M, Badn W, Darabi A, Siesjo P. PD-L1 expression by neurons nearby tumors indicates better prognosis in glioblastoma patients. J Neurosci 2013;33:14231-45.

10. Thierauf J, Veit JA, Affolter A, Bergmann C, Grunow J, Laban S, Lennerz JK, Grunmuller L, Mauch C, Plinkert P.K, Hess J, Hoffmann TK. Identifcation and clinical relevance of PD-L1 expression in primary mucosal malignant melanoma of the head and neck. Melanoma Res 2015;25:503-9.

11. Darb-Esfahani S, Kunze CA, Kulbe H, Sehouli J, Wienert S, Lindner J, Budczies J, Bockmayr M, Dietel M, Denkert C, Braicu I, Jöhrens K. Prognostic impact of programmed celldeath-1 (PD-1) and PD-ligand 1 (PD-L1) expression in cancer cells and tumorinfltrating lymphocytes in ovarian high grade serous carcinoma. Oncotarget 2016;7:1486-99.

12. Badoual C, Hans S, Merillon N, Ravel P, Benhamouda N, Levionnoks E, Besnier N, Gev A, Pere H, Tran T, Guerin CL, Chauvat A, Dransart E, Alanio C, Albert S, Bruneval P, Gridman WH, Lenoine FM, Oudard S, Johannes L, Olive D, Brasnu D, Tartour E. PD1-expressing tumor-infiltrating T cells are a favorable prognostic biomarker in HPV-associated head and neck cancer. Cancer Res 2013;73:128-38.

13. Feng Z, Xiang LL, Hai TW, Zuo PW, Bao LH, Hai FZ, Xiao LW, Li L. Programmed cell death 1 expression in esophageal squamous cell carcinoma and association with clinical characteristics. Indian J Cancer 2015;52:176-8.

14. Wu P, Wu D, Li LJ, Chai Y, Huang J. PD-L1 and survival in solid tumors: a meta analysis. PLoS One 2016;10:e0131403.

15. Stang A. Critical evaluation of the Newcastle-Ottawa scale for the assessment of the quality of nonrandomized studies in metaanalyses. Eur J Epidemiol 2010;25:603-5.

16. Tierney JF, Stewart LA, Ghersi D, Burdett S, Sydes MR. Practical methods for incorporating summary time-to-event data into metaanalysis. Trials 2007;7:16-24.

17. Higgins JP, Thompson SG, Deeks JJ, Altaman DG. Measuring inconsistency in meta-analyses. BMJ 2003;327:557-60.

18. DerSimonian R, Laird N. Meta-analysis in clinical trials. Control Clin Trials 1986;7:177-88.

19. Mantel N, Haenszel W. Statistical aspects of the analysis of data from retrospective studies of disease. J Natl Cancer Inst 1959;22:71948.

20. Begg CB, Mazumdar M. Operating characteristics of a rank correlation test for publication bias. Biometrics 1994;50:1088-101.

21. Egger M, Davey SG, Schneider M. Bias in meta-analysis detected by a simple, graphical test. BMJ 1997;315:629-34.

22. Zheng H, Liu X, Zhang JH, Shawn JR, Matthias W, Kong YX, Zhu LL, Zhu JJ, Monika J, Chandra PB. Expression of PD-1 on CD4+ $\mathrm{T}$ cells in peripheral blood associates with poor clinical outcome in non-small cell lung cancer. Oncotarget 2016;7:56233-40.

23. Shen T, Zhou L, Shen H, Shi C, Jia S, Ding G, Cao L. Prognostic value of programmed cell death protein 1 expression on CD8+ T lymphocytes in pancreatic cancer. Sci Rep 2017;7:7848-58. 
24. Harter PN, Bernatz S, Scholz A, Zeiner PS, Zinke J, Kiyose M, Blasel S, Beschorner R, Senft C, Bender B, Ronellenfitsch MW, Wikman H, Glatzel M, Meinhardt M, Juratli TA, Steinbach JP, Plate KH, Wischhusen J, Weide B, Mittelbronn M. Distribution and prognostic relevance of tumor-infltrating lymphocytes (TILs) and PD-1/PD-L1 immune checkpoints in human brain metastases. Oncotarget 2015;6:40836-49.

25. Webb JR, Milne K, Nelson BH. PD-1 and CD103 are widely coexpressed on prognostically favorable intraepithelial CD8 T cells in human ovarian cancer. Cancer Immunol Res 2015;3:926-35.

26. Mittal D, Gubin MM, Schreiber RD, Smyth MJ. New insights into cancer immunoediting and its three component phases-elimination, equilibrium and escape. Curr Opin Immunol 2014;27:16-25.

27. Duchnowska R, Peksa R, Radecka B, Trojanwski T, Jarosz B, Olszewski WP, Och W, Kozłowski W, Kowalczyk A, Loi S, Biernat W, Jassem J; Polish Brain Metastasis Consortium. Immune response in breast cancer brain metastases and their microenvironment: the role of the PD-1/PD-L axis. Breast Cancer Res 2016;18:43-51.

28. Chen KY, Cheng GP, Zhang FR, Zhang N, Li D, Jin JY, Wu JZ, Ying LS, Mao WM, Su D. Prognostic significance of programmed death-1 and programmed death-ligand 1 expression in patients with esophageal squamous cell carcinoma. Oncotarget 2016;7:30772-80.

29. Muenst S, Soysal SD, Gao F, Obermann EC, Oertli D, Gillanders WE. The presence of programmed death 1 (PD-1)-positive tumorinfiltrating lymphocytes is associated with poor prognosis in human breast cancer. Breast Cancer Res Treat 2013;139:667-76.

30. Sun L, Liu AL, Ku JW, Wei Y, Liu S, Zhang DY. Programmed death 1 expression on tumor tissues correlates with prognosis in esophageal squamous cell carcinoma patients. Clin J Exp Surg 2015;32:1817-9.

31. Xu H, Lin G, Huang C, Zhu W, Miao Q, Fan X, Wu B, Zheng X, Lin X, Jiang K, Hu D, Li C. Assessment of concordance between 22C3 and SP142 immunohistochemistry assays regarding PD-L1 expression in non-small cell lung cancer. Sci Rep 2017;7:169567034.

32. Herbst RS, Soria JC, Kowanetz M, Fine GD, Hamid O, Gordon MS, Sosman JA, McDermott DF, Powderly JD, Gettinger SN. Predictive correlates of response to the anti-PD-L1 antibody MPDL3280A in cancer patients. Nature 2014;515:563-7.

33. He Y, Rozeboom L, Rivard CJ, Ellison K, Dziadziuszko R, Yu H, Zhou C, Hirsch FR. PD-1, PD-L1 protein expression in non-small cell lung cancer and their relationship with tumor-infiltrating lymphocyte. Med Sci Monit 2017;23:1208-16.

34. Hamanishi J, Mandai M, Iwasaki M, Okazaki T, Tanaka Y, Yamaguchi K, Higuchi T, Yagi H, Takakura K, Honjo T, Fujii S. Programmed cell death 1 ligand1 and tumor-infiltrating CD8+ T lymphocytes are prognostic factors of human ovarian cancer. Proc Natl Acad Sci U S A 2007;104:3360-5.

35. Nakano O, Sato M, Naito Y, Orikasa S, Aizawa M, Suzuki Y, Shintaku I, Nagura H, Ohtani H. Proliferative activity of intratumoral $\mathrm{CD} 8(+) \mathrm{T}$-lymphocytes as a prognostic factor in human renal cell carcinoma: clinicopathologic demonstration of antitumor immunity. Cancer Res 2001;61:5132-6.

36. D’Angelo SP, Shoushtari AN, Agaram NP, Kuk D, Qin LX, Carvajal RD, Dickson MA, Gounder M, Keohan ML, Schwartz GK. Prevalence of tumor-infiltrating lymphocytes and PD-L1 expression in the soft tissue sarcoma microenvironment. Hum Pathol 2015;46:357-65.

37. Dai C, Lin F, Geng R, Ge X, Tang W, Chang J, Wu Z, Liu X, Lin Y, Zhang Z, Li J. Implication of combined PD-L1/PD-1 blockade with cytokine-induced killer cells as a synergistic immunotherapy for gastrointestinal cancer. Oncotarget 2016;7:10332-44.

38. Abdel RO. PD-L1 expression and outcome of advanced melanoma patients treated with anti-PD-1/PD-L1 agents: a meta-analysis. Immunotherapy 2016;8:1081-9.

39. Abdel RO. Correlation between PD-L1 expression and outcome of NSCLC patients treated with antiPD-1/PD-L1 agents: a metaanalysis. Crit Rev Oncol Hematol 2016;101:75-85. 